\title{
A route to anionic hydrophilic films of copolymers of L-leucine, L-aspartic acid and L-aspartic acid esters
}

\author{
W. L. Sederel, A. Bantjes and J. Feijen \\ Polymer Division, Department of Chemical Technology, Twente University of Technology, Enschede, \\ The Netherlands \\ (Received 11 November 1974; revised 24 March 1975)
}

\begin{abstract}
A series of copolymers of L-leucine and $\beta$-benzyl-L-aspartate [Leu/Asp(OBz)] covering the range $30-70 \mathrm{~mol} \%$ of L-leucine, was synthesized by the $N$-carboxyanhydride (NCA) method. The copolymers were characterized by elemental analysis, infra-red spectroscopy and viscometry. For all compositions high molecular weight copolymers were prepared with excellent film-forming properties. Tercopolymers of L-leucine, $\beta$-benzyl-L-aspartate and $\beta$-methyl-L-aspartate [Leu/Asp(OBz)/Asp(OMe)] were obtained after an ester interchange reaction (conversion $85-95 \%$ ) with the original copolymer systems. These tercopolymers were characterized by elemental analysis and i.r. spectroscopy. Films of the tercopolymers, cast from organic solvents, could be converted into hydrophilic films bysaponification of the methyl ester groups using alkaline water/organic solvent media. The hydrophilic films, which will be further investigated for their use as haemodialysis membranes were characterized by potentiometric titration and i.r. spectroscopy.
\end{abstract}

\section{INTRODUCTION}

During the last decade, there has been an intensified search for biomaterials. Synthetic polypeptides, well known as model compounds for the elucidation of natural processes, show great potential as biomaterials. These materials have already been studied for the utilization as biodegradable suture $^{1}$, artificial skin ${ }^{2,3}$, tissue implants ${ }^{4}$ or as membranes in haemodialysers ${ }^{5-8}$ and blood oxygenators 9 .

In haemodialysis membrane applications, where the materials are exposed to blood, it is necessary to get an understanding of the phenomena, which take place at the blood-material interface. In this respect negatively charged materials are of special interest, since it is thought that negatively charged surfaces repel platelets, ery throcytes and other blood elements, which are also negatively charged. Therefore, we are interested in the synthesis of a series of well characterized, negatively charged, water insoluble films, which can be made from synthetic polypeptides in a reproducible way.

Two approaches can be followed: (a) incorporation of Lglutamic acid or L-aspartic acid in hydrophobic polypeptides, such as poly (L-leucine); (b) crosslinking of polyacids such as poly (L-glutamic acid) or poly (L-aspartic acid). One disadvantage of many chemically crosslinked polymers is that the crosslinking (and sometimes the polymerization) is accomplished at the same time the membrane is being formed. As a result, it is often difficult to obtain reproducible pinhole free membranes. Therefore we decided to follow approach (a).

In principle copolymers of L-leucine and L-aspartic acid [ Leu/Asp $(\mathrm{OH})$ ] can be made by hydrogen bromide treatment of the corresponding $\beta$-benzyl-ester derivatives [Leu/ $\operatorname{Asp}(\mathrm{OBz})]$ (I). The copolymers of L-leucine and $\gamma$-benzylL-glutamate [ $\mathrm{Leu} / \mathrm{Glu}(\mathrm{OBz})]$ were treated in this way by Klein et al. ${ }^{6}$. The resultant polymers [Leu/Glu(OH)] were generally poorly soluble in common solvents. Membrane formation from mixtures of solvents yielded weak membranes.
On the basis of the results with the glutamic acid series an alternative pathway was chosen to reach our goal. This report describes the synthesis and characterization of hydrophilic films of high molecular weight copolypeptides of $L$ leucine, $\beta$-benzyl-L-aspartate, $\beta$-methyl-L-aspartate and Laspartic acid [Leu/Asp(OBz)/Asp(OMe)/Asp(OH)] (III). The films were obtained: (a) directly from films made of copolymers of L-leucine, $\beta$-benzyl-L-aspartate and $\beta$-methyl$\mathrm{L}$-aspartate [Leu/Asp(OBz)/Asp(OMe)] (II) by treatment with alkaline aqueous/organic solvent mixtures; and (b) by dissolving polymers (III) in pyridine and casting films from these solutions. The copolypeptides (II) were obtained from $\mathrm{L}$-leucine and $\beta$-benzyl-L-aspartate [Leu/Asp(OBz)] (I) copolymers via an ester interchange reaction.

\section{EXPERIMENTAL}

\section{Materials}

$\beta$-Benzyl-L-aspartate was synthesized by the method described by Benoiton ${ }^{10}$, (m.p. $220^{\circ} \mathrm{C}$ ). The monomers $\beta$ benzyl-L-aspartate-NCA (m.p. $125-126^{\circ} \mathrm{C}$ ) and L-leucine$\mathrm{NCA}\left(\mathrm{m} . \mathrm{p} .76^{\circ} \mathrm{C}\right)$ were prepared by methods described in the literature ${ }^{11,12}$.

Typical polymerization procedure for 50:50 Leu/Asp $(\mathrm{OBz})$ (I)

L-Asp(OBz)-NCA $(9.96 \mathrm{~g}, 40 \mathrm{mmol})$ was dissolved in a mixture of dry dioxane $(70 \mathrm{ml})$ and of dry benzene $(130 \mathrm{ml})$; L-leucine-NCA $(6.28 \mathrm{~g}, 40 \mathrm{mmol})$ was dissolved in dry benzene $(150 \mathrm{ml})$. The two solutions were filtered and introduced in the polymerization flask. Triethylamine (TEA) was used as an initiator at anhydride: initiator ratios (A/I) of 200 and 500. Polymerization reactions were allowed to proceed for 5 days at room temperature. A part of the clear viscous solution $(35 \mathrm{ml})$ was slowly poured into methanol $(500 \mathrm{ml})$ and the fibrous polymer was isolated and dried in vacuo at $50^{\circ} \mathrm{C}$. 
Synthetic copolypeptides for anionic hydrophilic films: $W$. L. Sederel et al.

Elemental analyses (I) (\%) Leu $x / A \operatorname{sp}(O B z)_{1-x}$

\begin{tabular}{llrr}
\hline$x$ & Element & Calculated & Found \\
\hline 0.70 & $\mathrm{C}$ & 64.01 & 63.92 \\
& $\mathrm{H}$ & 7.82 & 7.75 \\
0.67 & $\mathrm{~N}$ & 9.95 & 9.83 \\
& $\mathrm{C}$ & 64.04 & 63.67 \\
& $\mathrm{H}$ & 7.66 & 7.75 \\
0.60 & $\mathrm{~N}$ & 9.74 & 9.68 \\
& $\mathrm{C}$ & 64.09 & 63.36 \\
& $\mathrm{H}$ & 7.34 & 7.25 \\
0.50 & $\mathrm{~N}$ & 9.34 & 9.19 \\
& $\mathrm{C}$ & 64.15 & 63.71 \\
& $\mathrm{H}$ & 6.92 & 6.82 \\
0.40 & $\mathrm{~N}$ & 8.81 & 8.60 \\
& $\mathrm{C}$ & 64.21 & 63.63 \\
& $\mathrm{H}$ & 6.54 & 6.90 \\
0.30 & $\mathrm{~N}$ & 8.32 & 8.57 \\
& $\mathrm{C}$ & 64.26 & 64.06 \\
& $\mathrm{H}$ & 6.20 & 6.26 \\
& $\mathrm{~N}$ & 7.89 & 7.74 \\
\hline
\end{tabular}

\section{Leu/Asp(OBz)/Asp(OMe)(II)}

The polymer solution of (I) $(315 \mathrm{ml})$ was diluted with benzene $(300 \mathrm{ml})$ and the solution was heated to $65^{\circ} \mathrm{C}$ and treated with methanol $(150 \mathrm{ml})$ containing concentrated sulphuric acid $(6 \mathrm{ml})$ for $60 \mathrm{~h}$.

On cooling the polymer precipitated and the mixture was concentrated by evaporation. The resulting gel was dissolved in tetrahydrofuran (THF) and the solution was poured into water $(1.81)$. The polymer was isolated and washed with water until neutral and then dried in vacuo at $50^{\circ} \mathrm{C}$. The composition of copolymers (II) was determined by elemental analyses.

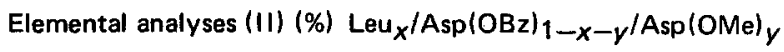

\begin{tabular}{llcr}
\hline & Element & Calculated & Found \\
\hline$x=0.70$ & C & 58.06 & 58.19 \\
$y=0.30$ & $H$ & 8.32 & 8.33 \\
& O & 21.74 & 22.26 \\
$x=0.60$ & C & 57.23 & 57.63 \\
$y=0.36$ & $H$ & 7.81 & 7.93 \\
& O & 23.52 & 24.30 \\
$x=0.50$ & C & 55.77 & 55.20 \\
$y=0.45$ & $H$ & 7.37 & 7.57 \\
& O & 25.64 & 25.40 \\
\hline
\end{tabular}

\section{Leu/Asp(OBz)/Asp(OMe)/Asp(OH) (III)}

II $(2 \mathrm{~g})$ was dissolved in THF $(50 \mathrm{ml})$ at $45^{\circ} \mathrm{C}$. The viscous solution was poured onto a glass plate and films were cast by use of a Dokter's knife. A second glass plate placed over the first one at a distance of about $1-2 \mathrm{~cm}$ was used to control the evaporation rate. The films $(20 \times 35 \mathrm{~cm}$, $20-40 \mu \mathrm{m}$ thick) were placed in a mixture of acetone $(500 \mathrm{ml})$ and $0.1 \mathrm{~N}$ sodium hydroxide $(500 \mathrm{ml})$ for various times $(0-4 \mathrm{~h})$. The films were then placed in $0.2 \mathrm{~N}$ hydrogen chloride $(200 \mathrm{ml})$. After washing with distilled water the films were dried and stored.

\section{Measurements}

Viscosity measurements of Leu/Asp(OBz) copolymers were carried out in Ubbelohde ty pe capillary viscometers at $25^{\circ} \mathrm{C}$. Elemental analyses were carried out in the section of Chemical Analyses of our Department (Mr W. Potman).
The mol \% of ionic groups in the end-products were determined by potentiometric titration in the same division (Dr M. Bos). Infra-red absorption spectra of solid films were measured with a Beckmann IR-33 spectrophotometer in the region $600-4000 \mathrm{~cm}^{-1}$.

\section{RESULTS AND DISCUSSION}

Hydrophilic copolymers of L-leucine, $L$-aspartic acid and Laspartic acid esters can be obtained by saponification of $\beta$ alkyl aspartate residues.

The $\beta$-alkyl ester groups can be introduced following two approaches: (a) copolymerization of L-leucine and $\beta$-alkyl-Laspartates; and (b) copolymerization of L-leucine with $\beta$ benzyl-L-aspartate, followed by an ester interchange reaction to convert the $\beta$-benzyl ester groups into $\beta$-alkyl ester groups $^{13}$. Until now poly( $\beta$-alkyl-L-aspartates) can only be prepared with low molecular weights, whereas $\beta$-benzyl-Laspartate-NCA can be polymerized with molecular weights over $100000^{13}$. Therefore we started with the synthesis of the as yet unknown high molecular weight random copolymers Leu/Asp(OBz) (I). In 1972 the synthesis of the low molecular weight sequential poly [Leu-Leu-Asp(OBz)] was reported ${ }^{14}$.

High molecular weight $\mathrm{Leu} / \mathrm{Asp}(\mathrm{OBz})(\mathrm{I})$ polymers are prepared by polymerization of the corresponding $\alpha$-amino acid $N$-carboxyanhydrides(NCAs). Optimum polymerization results are dependent on the choice of solvent(s) and molar ratios of the $\alpha$-amino acid-NCAs for a particular polymerization reaction.

Polymers (I), containing more than $50 \mathrm{~mol} \%$ of L-leucine can be polymerized best in benzene/dioxane (4:1 up to $6: 1$ $\mathrm{v} / \mathrm{v})$ mixtures. When the content of L-leucine in I is less than $50 \mathrm{~mol} \%$, the use of benzene/dioxane leads to lower yields and the polymerization solution becomes turbid. The polymerization of $\beta$-benzyl-L-aspartate-NCA in mixtures of dioxane and chloroform, using triethylamine as an initiator yields irreproducible products ${ }^{15}$. Notwithstanding the partial insolubility of $\beta$-benzyl-L-aspartate-NCA in chloroform, better results are obtained by using this solvent ${ }^{15}$. Therefore the 30:70 mixture of NCAs was polymerized in chloroform resulting in a polymer with a comparable composition.

Table 1 Reaction conditions and characterization of Leu/Asp(OBz) (I) copolymers ${ }^{\mathrm{a}}$

\begin{tabular}{|c|c|c|c|c|}
\hline $\begin{array}{l}\text { Molar ratios } \\
\text { of Leu-NCA and } \\
\text { Asp/(OBz)- } \\
\text { NCA }\end{array}$ & $\mathrm{A} / \mathrm{I}$ & $\begin{array}{l}\text { Polymer } \\
\text { composi- } \\
\text { tionb } \\
\text { (mol \% Leu) }\end{array}$ & $\begin{array}{l}\eta_{\mathrm{sp}} / c \\
(c=0.2 \\
\left.\mathrm{DCA}, 25^{\circ} \mathrm{C}\right) \\
(\mathrm{d} / / \mathrm{g})\end{array}$ & $\begin{array}{l}[\eta]]_{\mathrm{CH}^{2} 5^{\circ} \mathrm{C}} \\
(\mathrm{d} \mid / \mathrm{g})\end{array}$ \\
\hline $70: 30$ & 200 & 68 & 0.92 & $1.7^{\mathrm{c}}$ \\
\hline $67: 33$ & 200 & 67 & 0.96 & 2.8 \\
\hline $60: 40$ & 200 & 57 & 0.79 & - \\
\hline $60: 40$ & 500 & & 1.23 & 3.4 \\
\hline $50: 50$ & 200 & 47 & 0.56 & 1.7 \\
\hline 50:50 & 500 & & 1.52 & 5.3 \\
\hline $40: 60$ & 200 & 49 & 0.56 & - \\
\hline 40:60 & 500 & & 0.76 & - \\
\hline $30: 70$ & 200 & 26 & 0.53 & 1.1 \\
\hline
\end{tabular}

a The total NCA concentration is $5 \%$ by weight; triethylamine was used as an initiator. All the reactions were performed in benzene/ dioxane (4:1 up to: $6: 1 \mathrm{v} / \mathrm{v}$ ) mixtures except the 30:70 copolymer where chloroform was used

b Based on hydrogen and nitrogen elemental analysis (Figure 2) c In $\mathrm{CHCl}_{3}-\mathrm{DCA}(90: 10 \mathrm{v} / \mathrm{v})$ 


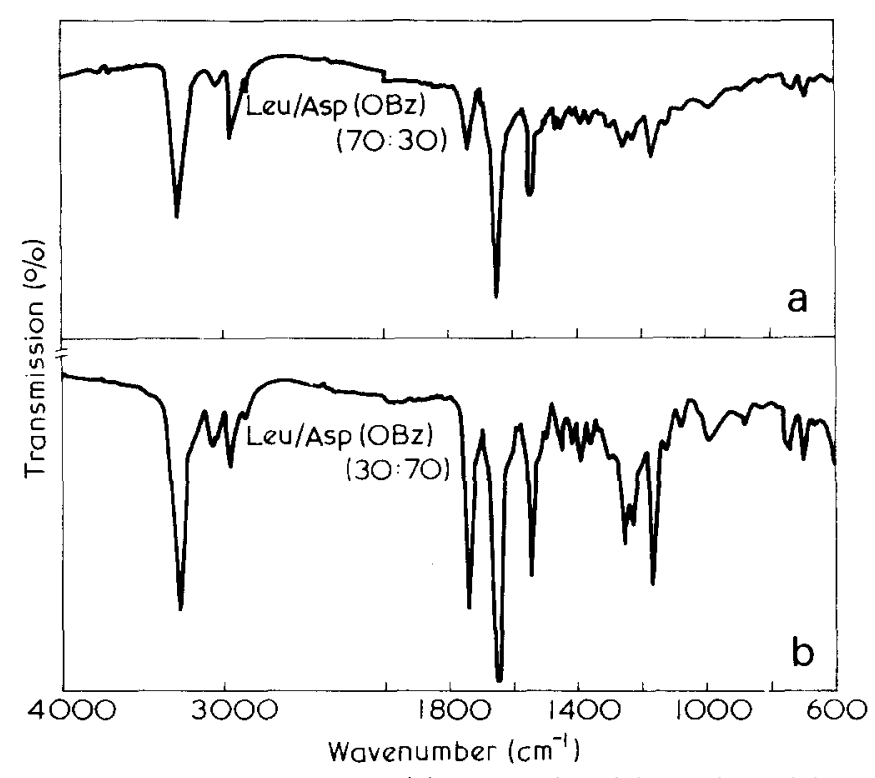

Figure 1 Infra-red spectra of (a) Leu/Asp(OBz) (70:30) and (b) Leu/Asp(OBz) (30:70). Films: 70:30 cast from benzene/dioxane; 30: 70 from chloroform

The compositions of polymers (I) based on molar ratios of NCAs used can be verified by elemental analyses (hydrogen and nitrogen). The results are given in Table 1. In general, good agreement was observed.

The polymers described in Table 1 are soluble in chloroform, except Leu/Asp(OBz), (70:30). All the polymers are soluble in dichloroacetic acid. Polymers containing from 50 to $80 \mathrm{~mol} \%$ L-leucine are soluble in benzene/dioxane $(4: 1 \mathrm{v} / \mathrm{v})$ mixtures. Non-solvents for all the polymers are alcohols, dimethylformamide (DMF), dimethylsulphoxide, acetonitrile and water.

Viscosity measurements on polymers (I) have been carried out at $25^{\circ} \mathrm{C}$ in dichloroacetic acid (DCA) solutions $\left(\eta_{\mathrm{sp}} / c, c=0.2 \mathrm{~g} / \mathrm{dl},\right)$ as well as in chloroform solutions $([\eta]$; $c=0.05-0.25 \mathrm{~g} / \mathrm{dl})$. It is clear that by using higher NCA-initiator $(A / I)$ ratios the viscosity values are increasing for the same polymer compositions. Preliminary o.r.d. measurements on Leu/Asp (OBz) (50:50) dissolved in DCA indicate that this polymer was not completely in the random coil conformation. Therefore it is not possible to determine the molecular weight of these polymers using the equation of Doty et al. ${ }^{16}$ for poly ( $\gamma$-benzyl-L-glutamate). The viscosity values in chloroform indicate a rod-like structure and/or strong association of the polymer chains.

Figure 1 shows the i.r. spectra of films of Leu/Asp $(\mathrm{OBz})$ (70:30 and 30:70). The absorption at $1745 \mathrm{~cm}^{-1}$ reveals the change in the amount of benzyl ester groups in the copolymers. The occurrence of the amide I band at about $1650 \mathrm{~cm}^{-1}$ and the amide II band at $1548 \mathrm{~cm}^{-1}$ in combination with a weak absorption at $1516 \mathrm{~cm}^{-1}$ indicates that in the films the polymer chains are predominantly in the $\alpha$ helical conformation.

The copolymers (I) are converted to II using the method of Bradbury et al. ${ }^{13}$. Viscous solutions of $\mathrm{I}( \pm 4 \% \mathrm{w} / \mathrm{v}$ in benzene/dioxane) are diluted with one volume of benzene. After the addition of an excess of methanol containing catalytic amounts of sulphuric acid reactions are performed at $65^{\circ} \mathrm{C}$ for $60 \mathrm{~h}$. The copolymers are isolated and purified by standard methods. Films having thicknesses from 20 to $40 \mu \mathrm{m}$ can be cast from 1, 1, 2, 2-tetrachloroethane (II, $70 \mathrm{~mol} \%$ L-leucine) or from THF (II, 60, 50 and $40 \mathrm{~mol} \%$
L-leucine). The ester interchange reaction can be followed by i.r. spectroscopy (Figure $2 a$ ).

When we compare the spectrum of II ( $50 \mathrm{~mol} \% \mathrm{~L}$-leucine) (Figure $2 a$ ) with the spectra of I (70 and $30 \mathrm{~mol} \% \mathrm{~L}$ leucine) (Figure 1), the peaks at 3080, 745-735 and $690 \mathrm{~cm}^{-1}$ (benzyl absorbance) disappear, whereas the peak at $1435 \mathrm{~cm}^{-1}$ (methyl) becomes stronger. These data in combination with elemental analyses of the methylated products indicate that the ester interchange occurs with $85-95 \%$ conversion.

Films of II originally based on 50,60 and $70 \mathrm{~mol} \%$ of Lleucine are saponified at room temperature by treatment for up to $4 \mathrm{~h}$ in $0.1 \mathrm{~N}$ sodium hydroxide/acetone $(1: 1 \mathrm{v} / \mathrm{v})$ mixtures. Wet films of Leu/Asp(OBz)/Asp(OMe)/Asp(ONa) are strongly swollen and are mechanically weak and difficult to handle. Upon treatment with acetone the films shrink

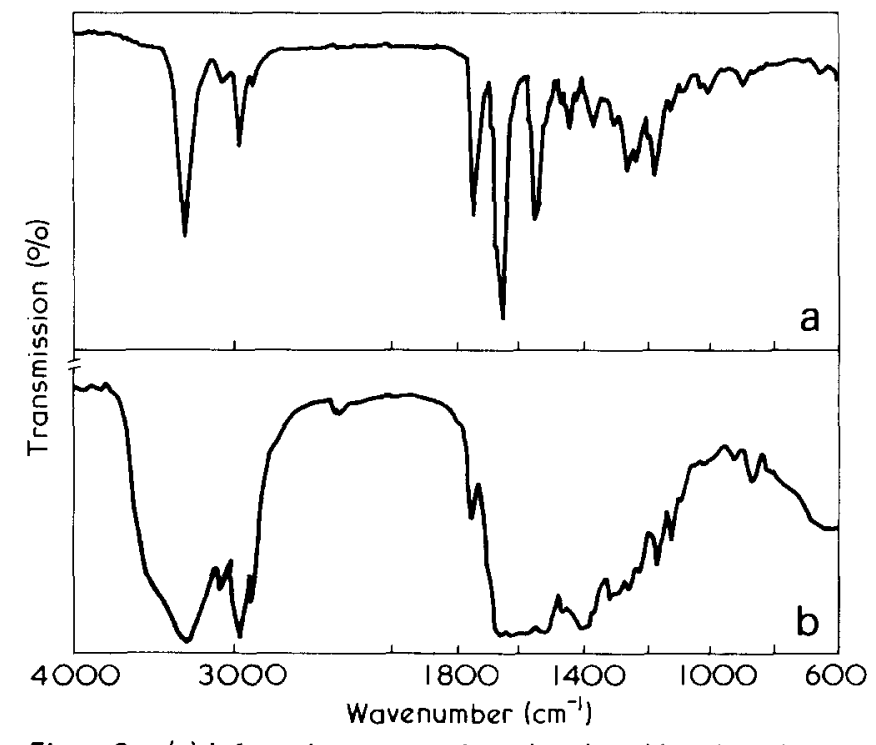

Figure 2 (a) Infra-red spectrum of Leu/Asp(OBz)/Asp(OMe), $50 \mathrm{~mol} \%$ of L-leucine. Film cast from tetrahydrofuran. (b) Infrared spectrum of partially hydrolysed Leu/Asp(OBz)/Asp(OMe)/ Asp(ONa) with $50 \mathrm{~mol} \%$ of L-leucine

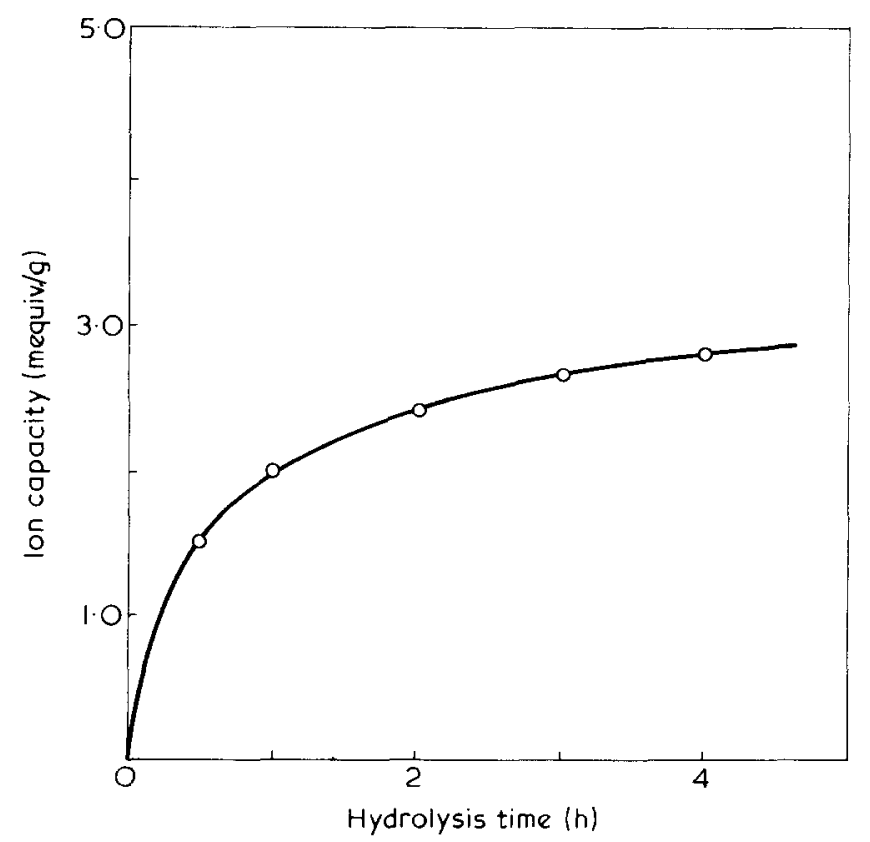

Figure 3 Ion capacity of hydrolysed film of Leu/Asp(OBz)/ Asp(OMe) (47:3:50) $50 \mathrm{~mol} \%$ of L-leucine ( $40 \mu \mathrm{m}$ thickness) as a function of hydrolysis time 


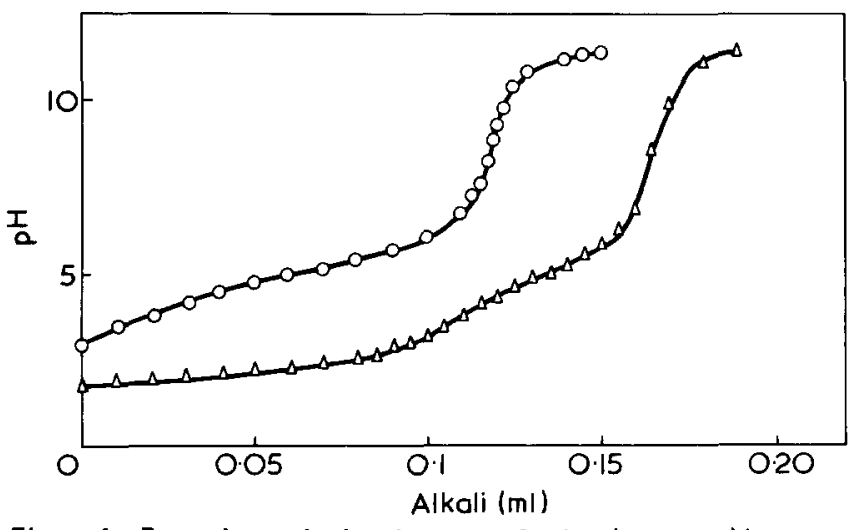

Figure 4 Potentiometric titration curve for Leu/Asp(OBz)/ Asp (OMe)/Asp(OH) and Leu/Asp(OBz)/Asp(OMe)/Asp(ONa). O, $52.10 \mathrm{mg}$ 'Leu/Asp(OH)' in $8 \mathrm{ml} 0.1 \mathrm{M} \mathrm{NaClO}_{4}$ titrated with $1.003 \mathrm{~N} \mathrm{NaOH} ; \triangle, 31.52 \mathrm{mg}$ 'Leu/Asp(ONa)' treated with $0.15 \mathrm{ml}$ $1.056 \mathrm{~N} \mathrm{HClO}_{4}$ in $10 \mathrm{ml} 0.1 \mathrm{M} \mathrm{NaClO}_{4}$ and titrated with $1.013 \mathrm{~N}$ $\mathrm{NaOH}$

markedly and can be better handled. After the reaction, alkali is removed by using an excess of $0.2 \mathrm{~N}$ hydrogen chloride. Wet films of Leu/Asp(OBz)/Asp(OMe)/Asp(OH) are much stronger than wet films of the sodium salt derivatives. Probably because acetone is a non-solvent for Leu/ $\operatorname{Asp}(\mathrm{OBz}) / \mathrm{Asp}(\mathrm{OMe}) / \mathrm{Asp}(\mathrm{ONa})$ saponification levels off after a certain time. For Leu/Asp(OBz)/Asp(OMe) (47:3:50) we found this to occur after $2 \mathrm{~h}$ (Figure 3), at 2.7 mequiv./g or $34 \mathrm{~mol} \%$ of $\mathrm{COOH}$ groups. When higher ionic contents are required treatment with $0.1 \mathrm{~N}$ sodium hydroxide in acetone for $2 \mathrm{~h}$ and then treatment with $0.1 \mathrm{~N}$ sodium hydroxide is an appropriate procedure. The copolymers (III) are soluble in pyridine (1.5-2.7 mequiv./g) or tetrahydrofuran. Therefore it is also possible to cast films from these solutions. The composition of these films will be more homogeneous than the films obtained directly after the saponification treatment.

The saponification can be followed by i.r. spectroscopy (Figure $2 b$ ). The mol \% of ionic groups in the polymer (III) is dependent on saponification times and film thicknesses.

The determination of the amount of ionic groups can be carried out by potentiometric titration in the presence of $0.1 \mathrm{~N} \mathrm{NaClO}_{4}$ by two ways: (a) titration of the acid form with sodium hydroxide; (b) titration of the sodium salt form by adding excess $\mathrm{HClO}_{4}$ and after equilibrium has been established, titration with sodium hydroxide (Figure 4). $\mathrm{A} \mathrm{p} K_{\mathrm{a}}$ value of 5.0 for $\mathrm{Leu} / \mathrm{Asp}(\mathrm{OBz}) / \mathrm{Asp}(\mathrm{OMe}) / \mathrm{Asp}(\mathrm{OH})$ (60\% Leu) is found graphically from Figure 4 using method (a). The method of least squares to obtain the best theoretical curve yields a value of $\mathrm{p} K_{\mathrm{a}}=5.18$.

\section{CONCLUSION}

A series of well characterized negatively charged films of random copolymers of L-leucine, $\beta$-benzyl-L-aspartate, $\beta$ methyl-L-aspartate and L-aspartic acid [Leu/Asp(OBz)/ $\operatorname{Asp}(\mathrm{OMe}) / \mathrm{Asp}(\mathrm{OH})]$ (III) was obtained after saponification of hydrophobic films of random copolymers of L-leucine, $\beta$-benzyl-L-aspartate and $\beta$-methyl-L-aspartate [Leu/Asp(OBz)/ Asp(OMe)] (II) in alkaline water/organic solvent media. Poiymers (II) were obtained after an ester interchange reaction with random copolymers of $L$-leucine and $\beta$-benzylL-aspartate, [Leu/Asp $(\mathrm{OBz})]$ (I).

The series of copolymers (I) covering the range 30$70 \mathrm{~mol} \%$ of L-leucine was synthesized by the $N$-carboxyanhydride (NCA) method.

\section{ACKNOWLEDGEMENTS}

Thanks are due to Mrs H. M. J. Hammink-Siers for typing the manuscript.

The contribution of $\mathrm{Mr} \mathrm{H}$. Hofs to part of this work is gratefully acknowledged.

\section{REFERENCES}

1 Miyame, T., Mori, S. and Takeda, Y. U.S. Pat. 3371069 (27.2.68)

2 Spira, M. Fisette, J., Hall, C. W., Hardy, S. N. and Gerow, F. J. J. Biomed. Mat. Res. 1969, 3, 213

3 Hall, C. W. et al. Trans. Am. Soc. Artif. Int. Organs 1970, 16,

4 Anderson, J. M., et al. 5th A. Biomat. Clemson Symp. 1973

5 Klein, E., May, P. D., Smith, J. K. and Leger, N. Biopolymers $1971,10,647$

6 Klein, E. and Smith, J. K. 3rd A. Rep. PB 210181 (1970-71) p 13

7 Klein, E., Lindholm, D., Smith, J. K. and May, P. D. 5th $A$. Contracters Conf. Artif. Kidney Program Nat. Inst. Arthr. Metab. Dis. 1973

8 Klein, E., Lindholm, D., Vieira, J. A., Smith, J. K. and May, P. D. ibid. 1973, p 162

9 Martin, E. C., May, P. D. and McMahon, W. A.J. Biomed. Mat. Res. 1973, 5, 53

10 Benoiton, L. Can. J. Chem. 1962, 40, 570

11 Karlson, R. H., Norland, K. S., Fasman, G. D. and Blout, E. R. J. Am. Chem. Soc. $1960,82,2268$

12 Fasman, G. D., Lindblow, C. and Bodenheimer, E. Biochemistry 1964, 3, 155

13 Bradbury, E. M., Carpenter, B. G. and Goldman, H. Biopolymers $1968,6,837$

14 D'Alagni, M., Bemporad, P. and Garofolo, A. Polymer 1972, 13, 419

15 Bradbury, E. M., et al. Proc. R. Soc. (A) 1960, 259, 11d

16 Doty, P., Bradbury, J. H. and Holtzer, A. M.J. Am. Chem. Soc. $1956,78,947$ 